\title{
EXPERIENCE WITH THE MANAGEMENT OF DEEP VEIN THROMBOSIS IN PATIENTS WITH SPINAL CORD INJURY
}

\author{
Part II : A Critical Evaluation of the Anticoagulant Therapy
}

\author{
By Arundhati Perkash, M.D., Ph.D. \\ Laboratory and Spinal Cord Injury Service, Veterans Administration Medical Center, \\ Palo Alto, California
}

DEEP vein thrombosis (DVT) leading to pulmonary embolism (PE) often fatal, is a major problem in patients with spinal cord injury (SCI) during the acute phase (Walsh \& Tribe, 1965; Watson, 1968; Silver \& Moulton, 1970; Hachen, 1974; Todd et al., 1976; Perkash et al., 1978). Anticoagulant therapy has been tried to prevent and treat thromboembolism in SCI patients using heparin alone (Casas et al., 1976), oral anticoagulants alone (Silver, 1974) or a combination of both (Hachen, 1974; Watson, 1974). The therapy and their regimens are based on the assumption that the pathogenesis of the DVT in SCI patients is similar to that occurring after major surgery.

The aim of the anticoagulant therapy is to lower the coagulability of the blood and thus prevent occurrence, recurrence, propagation and/or embolism of the thrombus. The anticoagulant is administered in doses which would impart maximum of hypocoagulability without jeopardising the patient's haemostasis significantly. Therefore, success or failure depends a great deal on how well this balance is maintained. Unfortunately, the margin between ineffective dose, effective dose and overdose is rather small; and the dose can vary unpredictably from patient to patient and even within the same patient from time to time. Past analysis of the anticoagulant therapy in patients other than spinal cord injury has shown that the recurrence of the thromboembolism has usually been associated with small doses, shorter duration of heparin therapy and with poor control of oral anticoagulants (Coon et al., 1969, 1972).

This paper presents a critical evaluation of the anticoagulant therapy received by eight acute SCI patients complicated with thromboembolism. The emphasis here is not on the statistics of a clinical trial, but on the outcome of therapy given and the problems involved in practical management of anticoagulation. The incidence and diagnosis of thromboembolism in these patients has been described in an earlier communication (Perkash et al., 1978).

\section{Methods and Materials}

Eight patients with acute spinal cord injury and thromboembolism admitted to the VA Medical Center, Palo Alto, California, between July 1976 and November 1977 were analysed. The interval between the time of injury and admission on the spinal cord injury service varied from to to 38 days. All patients were male aged 22 to 56 years. Levels of clinical lesion varied from $\mathrm{C}_{3}$ to a Tio. The diagnosis of DVT and PE (deep vein thrombosis and pulmonary embolism) was made as follows: all patients were carefully screened for DVT by physical examination, daily thigh and calf circumference measurements, and weekly electrical impedance plethysmography while they were confined to bed. Any 
patient with change in the thigh and calf circumference of over $1.5 \mathrm{~cm}$ was evaluated further. Impedance plethysmogram was obtained immediately, and, if needed, contrast venography was also done. Arterial blood gases, a chest radiograph, and serial dilution protamine sulphate test were done whenever possible in patients with clinical symptoms of pulmonary embolism.

The regime of anticoagulation was entirely by the individual choice of the physician. In general, when the diagnosis of DVT or PE was established an initial course of heparin therapy was followed by coumadin. Seven patients received heparin by continuous intravenous drip (IV) and one by intermittent 6-hourly IV push. The monitoring test was activated partial thromboplastin time (APTT) for heparin, and prothrombin time (PT) for coumadin. On admission, the following tests were performed on each patient:

I. Complete blood picture: haemoglobin, haematocrit, total and differential leucocyte count, red cell count, platelet count, reticulocyte count and assessment of red cell picture.

2. Coagulation profile: activated partial thromboplastin time (Morin \& Willoughby, 1975) using fibrolet (activated platelet factor reagent, BBL, Div. Becton Dickinson Co., Cockeysville, Md., 21030, U.S.A.) and Fibrometer; Quick's one-stage prothrombin time (Quick, I966) using rabbit brain and lung thromboplastin (Automated Simplastin, General Diagnostic Div., Warner, Lambert Co., Morris Plains, New Jersey, U.S.A.), and thrombin time (Grann et al., 1972) using bovine topical thrombin (Parke-Davis). Serial dilution protamine sulphate (SDPS) test (Gurrewich \& Hutchinson, I97I) was done where applicable.

The normal range in our laboratory is 25 to $40 \mathrm{sec}$ for APTT and II to I4 sec for prothrombin time. When the patient was on prophylactic subcutaneous heparin, the drug was not monitored. Monitoring was done for therapeutic heparin by APTT and for oral anticoagulation by PT. For either test, an increase in 2 to $2 \frac{1}{2}$ times the mean normal value was considered as adequate anticoagulation. For a lower level of anticoagulation value, I to $I \frac{1}{2}$ times the mean normal value was maintained.

The time schedule of monitoring varied with the response of the patient. For heparin therapy, monitoring test was performed 8 hourly in a patient with unstable response or getting high doses of heparin. The test was also performed immediately after a change in heparin dose. The monitoring schedule of the prothrombin time varied considerably with the individual physicians.

\section{Observations}

Relevant patient data in relation to anticoagulation therapy in eight acute SCI patients complicated with thromboembolisms is tabulated (see Table I). Six of the eight patients are presented below to illustrate the problems.

\section{Case Presentations}

Patient No. I. A 52-year-old white man was admitted to the SCI paraplegic centre Io days post-injury with extensive thrombosis in left calf, poplital and deep femoral veins. Initially, he received intermittent heparin, 6000 units ( 9 units $/ \mathrm{kgm} / \mathrm{hour}$ or 24000 units/day), every 6 hours for 8 days. Coumadin was simultaneously started at $5 \mathrm{mg}$ /day, raised to Io $\mathrm{mg} /$ day after 4 days due to failure to respond to the smaller dose, and was continued for 79 days. Coumadin was then stopped because of mild haematuria.

All through his anticoagulant therapy, both APTT and PT remained within normal limits and, therefore, he was never adequately anticoagulated during either heparin or 
TABLE I

Anticoagulant therapy in acute spinal cord injury patients with thromboembolism

\begin{tabular}{|c|c|c|c|c|c|c|c|c|c|c|c|c|}
\hline \multirow{2}{*}{$\begin{array}{l}\text { Patient } \\
\text { no. and } \\
\text { episode }\end{array}$} & \multirow{2}{*}{$\begin{array}{l}\text { Days } \\
\text { post } \\
\text { injury }\end{array}$} & \multirow[b]{2}{*}{$\mathrm{DVT} / \mathrm{PE}$} & \multirow[b]{2}{*}{ IV } & \multirow[b]{2}{*}{$\mathrm{U} / \mathrm{hr}$} & \multicolumn{2}{|c|}{ Heparin therapy } & \multirow[b]{2}{*}{ Comments } & \multirow[b]{2}{*}{$\begin{array}{l}\text { Days } \\
\text { given }\end{array}$} & \multirow{2}{*}{$\begin{array}{c}\text { Coum. } \\
\text { Hep. } \\
\text { over- } \\
\text { lap }\end{array}$} & \multicolumn{3}{|c|}{ Follow-up by Coumadin } \\
\hline & & & & & $\begin{array}{c}\text { Dose } \\
\text { U/24 hrs. }\end{array}$ & $\mathrm{U} / \mathrm{kg} / \mathrm{hr}$ & & & & $\begin{array}{l}\text { Dose } \\
\mathrm{mg} / \mathrm{d}\end{array}$ & $\begin{array}{l}\text { Weeks } \\
\text { given }\end{array}$ & Comments \\
\hline $2-\mathrm{EI}$ & 25 & Yes/? & Con & 250 to & 6,000 & 4 & Wide var. in & 15 & - & - & - & Not given \\
\hline \multirow{3}{*}{$3-\mathrm{EI}$} & & & & 1500 & 36,000 & 23 & D req. & & & & & \multirow{3}{*}{$\begin{array}{c}\text { Ad. acg. Co- } \\
\text { Trimo Pot. } \\
-\end{array}$} \\
\hline & 22 & Yes/? & Con & 2800 & 67,200 & 34 & $\begin{array}{l}\text { Inc. D req. } \\
\text { Good acg. }\end{array}$ & 7 & $4 \mathrm{~d}$ & $8-10$ & 17 & \\
\hline & & & Con & $\begin{array}{l}\text { I } 200 \text { to } \\
\text { I } 800\end{array}$ & 43,200 & 18 & $\begin{array}{l}\text { Dec. D Good } \\
\text { acg. }\end{array}$ & 9 & - & - & - & \\
\hline EII & 160 & No/Yes & - & - & 一 & - & - & 一 & - & 8-10 & - & - \\
\hline $4-\mathrm{EI}$ & 42 & Yes/No & Con & I 800 & 43,200 & 24 & Ad. acg. & I I & $3 d$ & $3-8$ & 17 & $\begin{array}{c}\text { Ad. acg. Co- } \\
\text { Trimo. Pot. }\end{array}$ \\
\hline EII & II 5 & No/Yes & - & 一 & 一 & - & Diag. by AT & - & - & - & - & - \\
\hline $5-\mathrm{EI}$ & 60 & Yes/No & Con & 1500 & 36,000 & 22 & Mod acg. R & 8 & $7 \mathrm{~d}$ & $5-10$ & 3 & Poor acg. R \\
\hline \multirow[t]{2}{*}{ EII } & 78 & No/? & Con & 1800 & 43,200 & 26 & Inc. $\mathrm{D}$ req. & 2 & - & - & - & - \\
\hline & & & Con & 1500 & 36,000 & 22 & Ad. acg. & 9 & $5 d$ & $10-18$ & I I & Ad. acg. \\
\hline 6-EI & Iro & No/Yes & Con & 1500 & 36,000 & 27 & Ad. acg. & 4 & $4 \mathrm{~d}$ & IO & 7 & Ad. acg. \\
\hline 7-EI & 46 & Yes/No & Con & 1200 & 28,000 & I7 & Ad. acg. & 4 & $4 \mathrm{~d}$ & $5-6$ & II & Min. acg. \\
\hline \multirow{2}{*}{$8-E I$} & 93 & Yes/No & Int & 1000 & 24,000 & I4 & Ad. acg. & 4 & $6 \mathrm{~d}$ & - & - & $\underline{-}$ \\
\hline & & & Int & 666 & 16,000 & 9 & Ad. acg. & 2 & $2 \mathrm{~d}$ & 8 & 8 & Min. acg. \\
\hline
\end{tabular}

Abbreviations

acg. = anticoagulation; Ad. = adequate; AT = autopsy; con = continuous; Co-Trimo. Pot. = potentiation of coumadin action by Co-trimoxazole; Coum. $=$ coumadin; $\mathrm{d}=$ days; $\mathrm{D}$ req. $=$ dose requirement; Dec. $=$ decrease; $\mathrm{DVT}=$ deep vein thrombosis; $\mathrm{E}=\mathrm{episode} ; \mathrm{Hep}$. = heparin; $\mathrm{IV}=$ intravenous route; Inc. $=$ increase; Int $=$ intermittent; $\mathrm{min}=$ minimum desired; $\mathrm{PE}=$ pulmonary embolism; $\mathrm{R}=$ recurrence of thromboembolism; $\mathrm{U}=$ units; var = variation 
coumadin therapy. The heparin dose as such is within the general recommended range, but it is low when his body weight is considered. Coumadin dose is high-average. The monitoring tests were performed but seemed to have not been considered. The DVT resolved, however, without recurrence and complications. Despite poor anticoagulation, he had two episodes of minor bleeding (mild haematuria and haemorrhoidal bleeding), both of which were considered to be unrelated to anticoagulant therapy.

Patient No. 2. A 56-year-old white male, who became tetraplegic $\left(\mathrm{C}_{4}\right)$ due to a fall, was admitted to SCI centre I5 days post-injury. On admission, he was dyspnic and hypoxic due to chronic obstructive pulmonary disease and paralysis. Eleven days after admission, he developed DVT in right leg involving calf, popliteal and femoral veins. He was given a bolus of 10000 units of heparin IV followed by continuous intravenous heparin at the rate of I000 units/hour which was raised to I 500 units/hour. Because of deterioration in the pulmonary condition, pulmonary embolism was also suspected, but lung scan was not possible due to acute cervical injury. SDPS was positive I in Io dilution. His $\mathrm{PaO}_{2}$ was $42 \mathrm{mmHg}$. During this period, his APTT shot up to three times normal, requiring reduction of heparin dose to Ioo units/hour. Heparin was then gradually raised to I000 units/hour, but APTT again shot to over I50 sec. Heparin was discontinued on 5/23/77. At that time, a tracheostomy was performed, and he was being maintained on the respirator. Heparin was resumed on 5/24/77 with good anticoagulation on 500 units/hour. On $5 / 27 / 77$, he received two units of packed cells; during the next 5 days his APTT became unresponsive to successive increasing doses of heparin to II 00 units/hour. Heparin was then discontinued.

This patient showed marked hour-to-hour variation in response to heparin. To keep him within the therapeutic range, careful 8-hourly monitoring was required. The fluctuations in heparin requirement seen in this patient were the widest in this series (Table I). Without an 8-hourly monitoring, he could readily pass from poor anticoagulation with a risk of thrombosis to hyper-anticoagulation with a risk to recurrence of thromboembolism. The reason for his hyperresponse to heparin during the phase of respiratory failure and resistance to heparin developing after blood transfusion is not clear.

Patient No. 3. A 31-year-old white man became quadriplegic (C6) on 7/19/77 in a diving accident. He was admitted to SCI centre 22 days post-injury. On admission, he had swelling of the right leg, shortness of breath, and $\mathrm{pO}_{2}$ of $52 \mathrm{mmHg}$. Rheogram and contrast venogram was positive for DVT. Pulmonary embolism was suspected, but patient's condition did not permit a lung scan.

$\mathrm{He}$ was started on continuous intravenous heparin with a dose of 1200 units/hour. An adequate APTT response was obtained only after the dose was raised to 2800 units/ hour. The heparin requirement remained high for 8 days. Then it dropped to I200I 500 units/hour for the next 7 days. Heparin was given for I6 days and then discontinued after an overlap with coumadin for 3 days.

On $8 / 21 / 77$, while on heparin, he developed a large haematoma in the right thigh. The patient was taking aspirin which was stopped lest it contributed to the bleeding. On $8 / 3 \mathrm{I} / 77$, while on coumadin therapy (PT was $2 \frac{1}{2}$ times normal), he developed mild haematuria which was thought to have been caused by intermittent catheterisation. Coumadin dose was lowered to keep prothrombin at twice the normal level. On 10/13/77, he developed urinary tract infection and was treated with Co-trimoxazole, resulting in marked potentiation of the coumadin action. Therefore, coumadin had to be omitted for 3 days. The response to coumadin returned to pre-Co-trimoxazole levels after I6 days of simultaneous use of both Co-trimoxazole and coumadin and remained stable. Coumadin therapy was planned to be given for 6 months.

About 5 months post-injury, when the patient had to make a trip out of state, coumadin was discontinued. At that time, he was moderately spastic in the lower limbs and was ambulating in the wheelchair. While on the trip (I60 days post-injury), he was hospitalised for pulmonary embolism with a positive lung scan. He was treated 
with coumadin and became asymptomatic in 2 days. Coumadin therapy was then planned to be continued for a year.

This patient required very large doses of heparin during the Ist week of thromboembolic episode, the largest in this series (Table I). The heparin requirement dropped sharply after 8 days of treatment. Without an 8-hourly monitoring, the patient may have been hyperanticoagulated over an extended period of 24 hours. In addition, the APTT came down to normal twice during heparin treatment because of a mechanical blockage of the IV dripset. Such interruption in heparin therapy during the acute recovery phase of thromboembolism poses risk of extension of the process, and can be detected only by more frequent monitoring.

Patient No. 4. A 56-year-old black man, quadriplegic (C5) since $12 / 5 / 76$ due to an automobile accident, was admitted to SCI centre 20 days post-injury. He had previous history of DVT in 1965. Forty-two days post-injury, he developed extensive thrombosis of left popliteal, femoral, and iliac veins. He was started on heparin intravenously with 500 units/hour which had to be raised to I800 units/hour before adequate anticoagulation was obtained. He was given heparin for I I days, the last 3 days overlapping with coumadin.

Coumadin produced adequate response on a dose of $5 \mathrm{mg} /$ day. While on coumadin for a week, Co-trimoxazole (two tablets per day) was also started. This lead to marked potentiation of coumadin action for the next Io days. Coumadin dose at that time was first lowered and then omitted for a day. Thereafter, he was maintained on 3 to $4 \mathrm{mg} /$ day with a PT of $\mathrm{I} \frac{1}{2}$ times for 55 days. After 55 days, a reduction in the dose of Co-trimoxazole was associated with an increase in coumadin requirement from 4 to $7.5 \mathrm{mg} /$ day. Coumadin was discontinued after 4 months of therapy.

He had one episode of mild rectal bleeding on heparin therapy when the PTT rose to IIO sec (normal up to $40 \mathrm{sec}$ ), possibly because the dose of heparin had not been monitored the previous day. He had one episode of mild haematuria during coumadin therapy when his PT was $30 \mathrm{sec}\left(2 \frac{1}{2}\right.$ times the normal). Anticoagulation was not discontinued for these two episodes of minor bleeding.

Fatal pulmonary embolism occurred Io days after the cessation of coumadin therapy (I 50 days post-injury, and 106 days after the previous episode of DVT).

Patient No. 5 (Fig. I). A 22-year-old white male became quadriplegic (C6) on 12/9/76 when he was sucked into the intake of a jet engine. He was admitted to the SCI centre 38 days after injury. Twenty-two days after admission (2/9/77) and 60 days post-injury, he developed extensive thrombosis in the right thigh veins. He was started on continuous intravenous heparin (I 500-I 800 units/hour) and coumadin simultaneously. The patient's prothrombin time was $I \frac{1}{2}$ times the normal on a dose of $7.5 \mathrm{mg}$ coumadin per day. After Io days, heparin was discontinued. During the subsequent 17 days, his prothrombin time fluctuated between $\mathrm{I} 2$ and $20 \mathrm{sec}$ and finally on 3/2/77 became unresponsive to a daily dose of $\mathrm{ro} \mathrm{mg}$ coumadin. The following day he developed difficulty in breathing and had rhonchi in both lungs, but the lung scans were negative. Nevertheless, he was considered a potential candidate for pulmonary embolism because of the recent episode of DVT. After 2 days of therapeutic heparinisation, lung signs on ausculation disappeared and the possibility of one minor embolic episode was considered.

Initially, he was started on continuous intravenous heparin with a bolus of 10000 units and continuous IV infusion of 750 units/hour, but did not show adequate anticoagulant response until a successive increase in heparin dose reached a level of 1750 units/hour on the 5th day. Thereafter, he required a dose of 1500 units/hour to keep APTT twice the normal value. Heparin was stopped after Io days. Coumadin was started on the 7 th day of heparin therapy. Prothrombin time reached to twice normal after a successive increase in the dose of coumadin to $17.5 \mathrm{mg} /$ day. He was maintained on coumadin, $15 \mathrm{mg} /$ day for 4 weeks, after which his requirement decreased to $7 \mathrm{mg} /$ day. Coumadin was discontinued after 47 days of therapy to prepare the patient for transuretheral sphincterotomy with prophylactic low dose heparin. Subcutaneous heparin was 


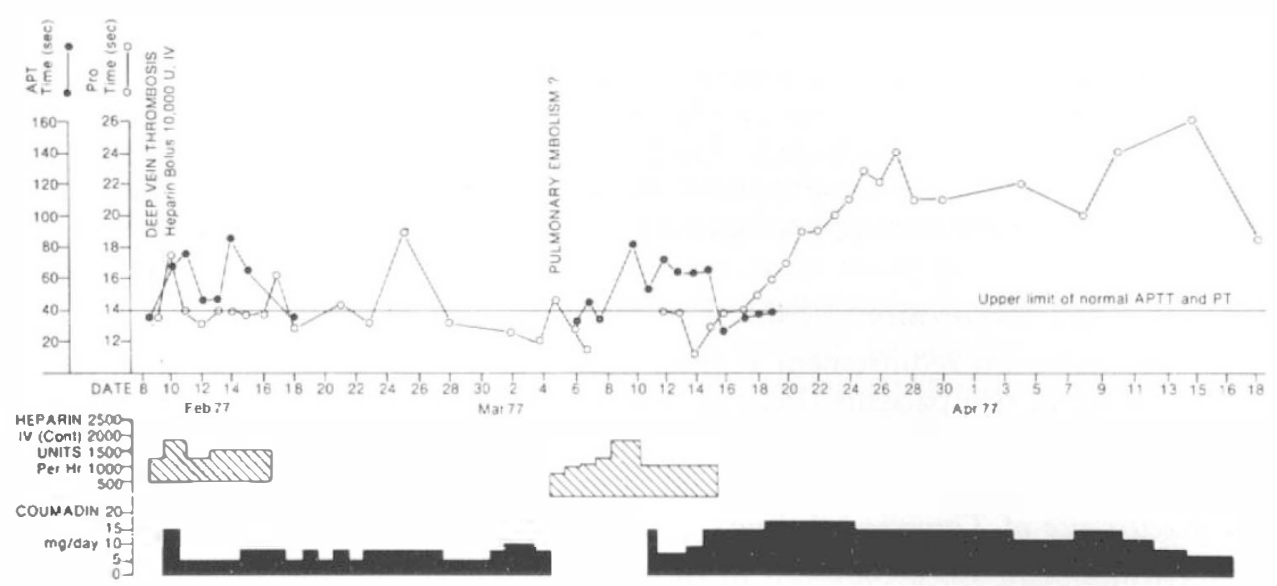

FIG. I

Patient No. 5: The variations in anticoagulation response to heparin and coumadin and its relationship with recurrence of thromboembolism.

given in the doses of 5000 units every 12 hours for 7 days starting 2 hours before surgery on 5/5/77. A second similar course of prophylactic heparin was given for a repeat sphincterotomy 32 days after the first one without complications. Coumadin therapy was resumed and continued for a total of 5 months from the day the DVT was initially diagnosed.

Patient No. 6. Relevant data in Table I

Patient No. 7. Relevant data in Table I.

Patient No. 8. A 3I-year-old white male became paraplegic when he was sucked into the intake of a jet engine. He underwent partial gastrectomy for an ulcer I9 days postinjury. Following that, he developed acute pancreatitis. Twenty-three days after admission (9I days post-injury), he developed left leg DVT involving calf, popliteal and femoral veins. He was given intermittent intravenous heparin, 5000 units every 4 hours for 3 days with adequate anticoagulation. He developed mild haematuria which was thought to be catheter-induced. Nevertheless, in order to have better control on heparin administration, he was switched to continuous intravenous heparin, and showed adequate anticoagulation on 1000 units/hour for $2 \mathrm{I}$ days. He had to be switched back to intermittent heparin because of unavailability of IVAC pump and received heparin for 3 more days.

Subsequently, he received coumadin for 54 days. In view of a haemorrhagic episode, he was maintained on a lower level of anticoagulation (about $\mathrm{I} \frac{1}{2}$ times normal) and required 5-IO $\mathrm{mg}$ of coumadin/day.

\section{Analysed Data}

\section{Prophylactic Subcutaneous Low Dose Heparin Therapy}

One patient (Patient No. 7) received prophylactic subcutaneous heparin, 5000 units subcutaneous twice daily for 20 days after admission. He developed thromboembolism 9 days (46th day post-injury) after the discontinuation of prophylactic therapy. 


\section{Heparin Requirements (Table I)}

The overall heparin requirement for adequate anticoagulation (APTT 2 to $2 \frac{1}{2}$ times normal) ranged between 6000 units ( 4 units $/ \mathrm{kg}$ per hour) to 67000 units/ 24 hours (34 units $/ \mathrm{kg}$ per hour). In two patients (Patient Nos. 2 and 3), the requirement varied considerably even during the course of therapy, the range being 6000 to 28000 units/24 hours, and 3800 to 67200 units/24 hours respectively.

\section{Coumadin Requirements (Table I)}

The coumadin requirement ranged from 5 to $18 \mathrm{mg} /$ day. Drug interaction was observed in two patients (Patient Nos. 3 and 4) in whom marked potentiation of coumadin action occurred during simultaneous Co-trimoxazole therapy.

\section{Recurrence of Thromboembolism}

Thromboembolism recurred in three patients (Patient Nos. 3, 4, and 5). It was associated with inadequate dose in one patient (Patient No. 5) and early discontinuation of coumadin therapy in the other two (Patient Nos. 3 and 4).

\section{Haemorrhage during Anticoagulant Therapy}

Five patients out of eight had a total of seven episodes of minor bleeding which consisted of mild haematuria in four patients (one during heparin and three during coumadin therapy), melena in one patient (during heparin therapy) and haematoma thigh in two patients (one during heparin and the other during coumadin therapy).

The two instances of haematoma thigh were considered to be a consequence of anticoagulant therapy. In Patient No. 3, a large haematoma occurred in the left thigh during heparin therapy at a time when the PTT response to a previously adequate dose of heparin (2800 units/hour) had increased suddenly. The heparin dose was reduced to 400 units/hour. He was also receiving aspirin at the same time which was discontinued. The anticoagulant therapy by coumadin was discontinued in only one patient (Patient No. 7) because of a haematoma.

\section{Discussion}

The regime of the prophylactic and therapeutic management of established deep vein thrombosis and/or embolism varies widely (deTakats, 1976) and is reflected to some extent in the management of patients by different physicians in the series. Many of the problems encountered in anticoagulant management of spinal cord injury patients are inherent in the heparin therapy itself, irrespective of the type of patient involved, while others pertain to the specific clinical situation of the spinal cord injury.

It is undisputed that the acute spinal cord injury patients are at high risk for thromboembolic complication and should receive prophylactic anticoagulation, but there is no unanimity as to the choice of anticoagulant and the period for which it should be given. Some of the factors which may be of significance in prophylaxis were discussed in an earlier communication (Perkash et al., 1978). The guidelines derived from our experience of therapeutic anticoagulation are discussed here. In both situations, we feel that the outcome of the therapy will 
improve considerably if anticoagulation regime is flexibly tailored to the individual clinical status of each patient.

For prophylaxis of thrombosis either oral anticoagulants or low dose heparin can be used. Both are intended to keep the concentration of Factor Xa below the critical level which would otherwise lead to thrombin generation and thrombosis. The superiority of one over the other has not yet been proven. The choice will depend upon the convenience, cost of administration and the feasibility of monitoring. Minidose heparin administration costs more but does not require monitoring. Oral anticoagulants are cheaper but need to be monitored. Patients with minimal or low level spinal cord injury, and not associated with high risk factors for DVT, may not be given any prophylactic anticoagulation. Those with extensive or high level spinal cord injury and/or with high risk factors such as fractures requiring casts, crush injuries, burns, disseminated cancer, extensive tissue trauma, persistent infection and those with previous history of thromboembolism should receive either low dose heparin or oral anticoagulants. Alternatively,low dose heparin is started immediately and later replaced by coumadin if oral anticoagulation is desired, to be continued for at least 12 weeks or until the return of full spasticity. The period of prophylactic anticoagulant administration may be extended 4 to 6 months, if any of the risk factors continue to exist. Major surgical procedures involving large tissue trauma, should be covered with low dose heparin (Wessler \& Yin, 1973). If the patient has been on oral anticoagulant prior to surgery, it should be discontinued 48 hours before surgery, the low dose heparin administered subcutaneously in doses of 5000 units every 12 hours, starting 2 hours prior to surgery and continued for I week after surgery. The coumadin therapy can be resumed again if required.

Once DVT and/or a PE has occurred the thrombin already generated can be neutralised only by large doses of heparin. Oral anticoagulants cannot neutralise existing thrombin. Therefore, in a patient with established thrombosis and/or embolism heparin in larger doses is the anticoagulant of choice for the initial treatment. The anticoagulation response of a weight-adjusted dose of heparin varies with a large number of factors including potency of commercial product, dose, route and mode of administration, the individual tolerance of the patient, the hepatic and renal clearance, the alterations induced by trauma, shock, operation, haemorrhage, burns, infection, presence and extent of thromboembolism, and the sensitivity and precision of the clotting test employed to assess the heparin response (deTakats, I976; Coon, 1978). When the decision to give heparin therapy has been made, the question arises regarding the doses, route and mode of administration, duration of therapy, and whether to monitor the treatment or not. A due consideration for all the factors is required for adequate heparinisation:

(I) Dose of heparin. The general recommended dose for heparin in DVT is from 25000 to 45000 units per 24 hours (Thomas, 1978) to be administered with (Gurewich, 1976; Gallus, 1976) or without adjustment by monitoring (Wessler \& Geitel, 1976). In pulmonary embolism, the recommendations are for an initial treatment to be with higher doses of 60000 to 120000 units per 24 hours intravenously, followed by reduction to 30000 to 45000 units per 24 hours. However, it is apparent from our review that the heparin requirement was within the aboverecommended range only in four patients. In Patient No. 2, the smallest dose was as low as 6000 units per 24 hours. In Patient No. 3, heparin dose as large as 67200 units per 24 hours was required for 8 days before the requirement decreased to 43,200 units per 24 hours. Without dose adjustment if one was to remain within 
the recommended range, Patient No. 2 would be hyper-anticoagulated at a given period and Patient No. 3 would not be anticoagulated at all for 6 days during the acute phase of DVT.

The need for a flexible protocol for heparin is obvious. We therefore recommend to start heparin therapy with a bolus of 5000 units followed by a constant infusion of a dose of I4 units per $\mathrm{kg}$ of body weight per hour (about 1000 units per hour, or 24000 units per 24 hours). The dose should be adjusted by an increase or decrease of 200 units each time until the desired anticoagulation is reached.

The requirements to maintain an effective blood concentration are known to vary considerably despite weight-adjusted doses (O'Sullivan et al., I968). In our series, Patient No. 8 was anticoagulated by $\mathrm{I} 4$ units of heparin per $\mathrm{kg}$ of body weight per hour while Patient No. 3 required 34 units of heparin per $\mathrm{kg} /$ body weight per hour. Furthermore, the response in the same patient may vary widely during the course of the treatment as exemplified by Patient No. 2. It is probably because of this unpredictability and variation in response to heparin that Meinecke (1965) found it difficult to control the levels of anticoagulation in spinal cord injury patients adequately. In a poorly responding patient, it is necessary to raise the dose of heparin to achieve an APTT value of 2 to $2 \frac{1}{2}$ times the normal because in our observation, as well as previous studies, recurrences were associated with APTT lower than this range irrespective of the dose of heparin given (Basu et al., I972).

(2) Control of heparin therapy. We found monitoring the heparin therapy to be indispensable. The purpose of monitoring is twofold: first, to assure the desired degree of anticoagulation so as to prevent extension or embolisation of thrombus, and second to prevent undesirable prolongation of clotting time of blood so as to minimise the risk of haemorrhage. The monitoring of heparin requires manipulation according to the route and mode of administration. In all instances, the value aimed at is 2 to $2 \frac{1}{2}$ times the mean of normal range of the laboratory test used (not the initial value of the patient which may be shortened). The test is done before starting the therapy. If a bolus is given and is followed by continuous intravenous drip, the test should be repeated 2 to 3 hours after the initiation of therapy and after every increase or decrease in dose of heparin to assess the anticoagulation and further adjustment of the dose. Thereafter, it is repeated once every day. In a critically ill patient, those with unstable clotting times, and in patients receiving more than IOoO units of heparin per hour, the test should be repeated every 6 to 8 hours. With continuous intravenous drip, the blood sample for monitoring test can be drawn any time, but with intermittent intravenous therapy it should be done 4 hours after the last injection and before the next dose.

When a patient previously responding well to anticoagulation suddenly shows a decreased response to the same or even increased dose, the patient is either not receiving the anticoagulant (such as with blocked IV drip) or has become truly resistant. When the patient manifests true increase in resistance to the anticoagulation, the possibility of an extension of the thrombus and/or embolism should be considered (Patient No. 5) and will usually require an increase in dose (Simon et al., 1978).

(3) Mode of heparin administration. The continuous infusion of heparin has been found to be significantly safer (Glazier et al., 1976) as it produces more even clotting times, but the safety and efficacy of the continuous heparin infusion 
depends very much on careful supervision by the nursing staff and adequate laboratory monitoring of the treatment. If this is not possible, then intermittent therapy is a good alternative (Gallus, I976).

(4) The duration of heparin therapy. The period recommended for heparin therapy for an episode of thromboembolism varies from 2 to Io days. We consider a minimum of IO days of heparin therapy to be essential as this is the time required for thrombi to be covered by endothelium and rendered inactive for propagation (Genton, 1974). The last 3 to 5 days of heparin therapy should be overlapped with oral anticoagulants. The heparin should only be discontinued after effective anticoagulation with coumadin has been established.

(5) Oral anticoagulants. The importance of adjusting doses adequate to maintain the prothrombin time to 2 to $2 \frac{1}{2}$ times has implications similar to those already discussed for heparin therapy and is well exemplified by Patient No. 5. It is helpful to obtain the baseline prothrombin time of the patient before starting heparin therapy. Prothrombin time is performed every day for the first 3 to 5 days until the desired anticoagulation is stabilised. Thereafter, it can be repeated weekly or biweekly. A haemorrhagic complication or drug interaction may require a temporary return to daily or alternate day monitoring. As in heparin therapy, when a patient on coumadin suddenly becomes resistant, the patient is either not receiving the drug or has developed true resistance. Inadvertent or deliberate omission of oral anticoaguiant is not uncommon and should be ruled out. The two common causes of true resistance are onset of thromboembolism (Patient No. 5) and excess intake of vitamin $\mathrm{K}$ through diet or multivitamin pills.

The time for which coumadin prophylaxis should be continued will vary according to the diagnosis and complications in individual patients. We would recommend coumadin for $\mathrm{I} 2$ weeks following uncomplicated and moderate DVT, and 6 months to I year in patients with extensive DVT and/or pulmonary embolism (Brozovic, 1978). Recurrent pulmonary embolism may require even more prolonged ( $\mathrm{I}$ to 2 years) anticoagulation. Patients with other associated implications such as hip fracture, prosthetic heart valves, and myocardial infarction will require special anticoagulation regime.

(6) Drug interactions. A large number of drugs commonly used interact with coumadin leading to either increase or decrease in its anticoagulant action (Soloway, 1974). The doses of the anticoagulant will need adjustment accordingly. We encountered marked potentiation of coumadin action by Co-trimoxazole in two patients (Patient Nos. 2 and 3). Both patients were already receiving coumadin when Co-trimoxazole was started. Because of the marked potentiation of the action of coumadin, the dose was omitted for 2 to 3 days and then resumed at a lower dose. After Io days, the degree of potentiation decreased and prothrombin time stabilised at a level similar to the pre-Co-trimoxazole therapy on a lower dose of coumadin. To prevent hyper-anticoagulation, it was necessary to perform the prothrombin time every day or on alternate days until the new equilibrium was established between the two drugs. A change in dose of either drugs also required a prompt check on prothrombin time.

Drug interactions are not common with heparin. However, one of the important considerations during heparin therapy is that aspirin should not be administered simultaneously. In patients who are on heparin, platelets are the 
only blood components providing haemostasis. Aspirin inhibits platelet aggregation and prolongs bleeding time. Tylenol is not known to have this effect and may be given for analgesia during heparin therapy. A periodic check on platelet count is also advised for patients on heparin because thrombopenic patients are at extra risk of bleeding during heparin therapy.

(7) Haemorrhagic complications. A bleeding episode per se is not an indication for discontinuation of anticoagulation. An evaluation should be made in each patient independently with regards to the haemorrhage in relation to its severity and relationship to anticoagulation, and the risk from thromboembolism against the risk from haemorrhage. In the face of a minor bleeding, a patient at high risk for thrombosis can be maintained on a lower level of anticoagulation (at $1 \frac{1}{2}$ times the normal level) rather than withdraw the anticoagulation completely (Wessler, 1974). The risk of thrombosis against the risk of haemorrhage should be evaluated in each patient independently. In our series, significant haemorrhage did not occur even with high doses of heparin as long as the APTT was within the therapeutic range.

(8) Recording of anticoagulation response. Serial recording of anticoagulant therapy with regards to date, time, dose of anticoagulant, clotting test response, and clinical improvement was very hopeful in evaluating the progress of the patient and outcome of therapy especially in a more complicated patient (Patient No. 5, Fig. I).

\section{SUMMARY}

Eight acute spinal injury patients with deep vein thrombosis and/or pulmonary emboli are presented with an in-depth analysis and management of anticoagulation therapy. Special considerations for acute spinal cord injury patients with regards to prophylactic and therapeutic anticoagulation by heparin and coumadin are discussed. There was a wide variation in the requirement of heparin and/or coumadin to maintain effective coagulability which could only be elicited by frequent laboratory monitoring. Inadequate dose and shorter duration of administration of anticoagulant resulted in recurrence of thromboembolism in three out of eight patients in the present series. Haemorrhagic complications were minor and easily manageable. Co-trimoxazole potentiation of coumadin action occurred in two of our patients and it requires special mention as the drug is used increasingly in the treatment of urinary tract infections.

\section{RÉSUMÉ}

Huit malades avec thrombose des veines profondes et/ou embolie pulmonaire ont été examinés pendant leur traitment anticoagulant. Nous discutons ici des problems specifiques de l'utilisation prophylactique et therapeutique de l'heparine et de la coumadine chez les malades avec lésion de la moelle epinière. Nous avons trouvés une grande variation dans la posologie nécessaire pour parvenir à un bon état d'anticoagulation et la connaissance du taux du médicament dans le sang fut necessaire pour y arriver. Les doses insuffisantes et les traitments trop courts amenaient un retour de la thrombose chez 3 de 8 malades. Nous n'avons pas eu de complications hémorrhagiques serieuses. Il est important de mentioner que nous avons observé deux fois une potentialisation de l'action de la coumadine par la Co-trimoxazole qui est un médicament largement utilizé pour le traitment des infections de la vessie. 


\section{ZUSAMMENFASSUNG}

Acht akut rückenmarkverletzte Patienten mit Profunda-Venenthrombose und/oder Lungenembolie sind hier, zusammen mit einer gründlichen Analyse und Behandlungsbeschreibung der Anticoagulationstherapie dargestellt. Besondere Berücksichtigungen fur akut Rückenmarkverletzte mit Bezug auf die vorbeugende und therapeutische Anticoagulation mit Heparin und Coumadin sind erörtert. Es bestand eine weitreichende Verschiedenheit in dem Heparins-und/oder Coumadins Bedürfnis eine wirkungsvolle Gerinnbarkeit zu unterhalten, die auch dann nur durch häufig wiederholte Laborüberwachung bestätigt werden konnte. Ungenügende Dosis und kürzere Darreichungsfortdauer des Anticoagulans hatte die Wiederkehr der Thrombusembolie in drei von acht Patienten in der vorliegenden Gruppe zur Folge. Hämorrhagische Komplikationen waren unbedeutend und leicht zu handhaben. Co-trimoxazole Arzneipotenzierung der Coumadinwirkung war in zwei unserer Patienten eingetreten, und dies sollte hervorgehoben sein, denn Co-trimoxazole wird mehr und mehr für die Behandlung der geschlechts-harnapparatbezüglichen Infektionen verwendet.

Acknowledgement. I am thankful to V. Prakash, M.D., G. Sullivan, M.D., M. Javier, M.D., and F. Rhame, M.D. for helping me retrieve data and diligent follow-up of the patients.

\section{REFERENCES}

Basu, D., Gallus, A., Hirsh, J. \& Cade, J. (1972). A prospective study of the value of monitoring heparin treatment with the activated partial thromboplastin time. N. Engl. F. Med., 287, 324-327.

Brozovic, M. (1978). Oral anticoagulants in clinical practice. Semin. Hemat., 15, 27.

Casas, E. R., SANChez, M. P., ARIAS, C. R. \& Masip, J. P. (1976). Prophylaxis of venous thrombosis and pulmonary embolism in patients with acute traumatic spinal cord lesions. Paraplegia, 14, I78-183.

Coon, W. W. \& WILlIS, III, P. W. (I972). Thromboembolic complications during anticoagulant therapy. Arch. Surg., I05, 209.

Coon, W. W., WILlIS, P. W. \& SyMONS, M. J. (1969). Assessment of anticoagulant treatment in venous thromboembolism. Ann. Surg., 170, 559.

DETAKats, G. (1976). Heparin: the need for a flexible protocol. Amer. F. Surg., r32, I.

Estes, J. W. \& Poulin, P. R. (I974). Pharmacokinetics of heparin. Distribution and elimination. Thromb. Diathes. Haemorrh., 33, 26-37.

Galius, A. S., Hirsh, J. \& O'Brien, S. E. (I976). Prevention of venous thrombosis with small subcutaneous doses of heparin. F. Amer. Med. Assn., 235, 1980.

Genton, E. (I974). Guidelines for heparin therapy. Ann. of Int. Med., 80, 77-82.

GranN, V., Homewood, K. and GoldEN, W. (I972). Polybrine neutralization as a rapid means of monitoring blood heparin levels. Amer. F. Clin. Path., 58, 26-32.

GuREWICH, V. (I976). Guidelines for the management of anticoagulant therapy. Sem. Thromb. Hemost., 2 (3), I 76.

GUREWICH, V. \& HUTCHINSON, E. (I97I). Detection of intravascular coagulation by a serial dilution protamine sulfact test. Ann. Int. Med., 75, 895-902.

HACHEN, H. J. (1974). Anticoagulant therapy in patients with spinal cord injury. Paraplegia, 12, I76-I87.

Hachen, H. J., Rossier, A. B., Bouvier, C. A. \& Ritschard, J. (1974). Deficiency within the extrinsic prothrombin activator system in patients with acute spinal cord injury. Paraplegia, 12, 132-138.

Meinecke, F. W. (1965). Discussion on 'Phlebothrombosis and pulmonary embolism in paraplegia' by Walsh and Tribe. Paraplegia, 3, 2 ro.

MoRIN, R. J. \& WilloughBY, D. (I975). Comparison of several activated partial thromboplastin time methods. Amer. F. Clin. Path., 64, 24I-247.

O'Sullivan, E. F., Hirsch, J., McCarthy, R. A. \& Degruchy, G. C. (I968). Heparin in the treatment of venous-thromboembolic disease: administration, control and results. Med. F. Australia, II, I 53.

Perkash, A., Prakash, V. \& Perkash, I. (1978). Experience with the management of thromboembolism in patients with spinal cord injury. Part I: Incidence, diagnosis and role of some risk factors. Paraplegia, 16, 318-327. 
Salzman, E. W., Deykin, D. \& Shapiro, R. M. (I975). Management of heparin therapy. N. Engl. F. Med., 292, 1046-1050.

SILVER, J. R. (1974). The prophylactic use of anticoagulant therapy in the prevention of pulmonary emboli in one hundred consecutive spinal injury patients. Paraplegia, 12, I88-I96.

Silver, J. R. \& Moulton, A. (I970). Prophylactic anticoagulant therapy against pulmonary emboli in acute paraplegia. Brit. Med. F., 2, 338-340.

Simon, T. L., Hyers, T. M., Gaston, J. P.\& Harker, L. A. (I978). Heparin parmacokinetics: increase requirements in pulmonary embolism. Brit. F. Haemat., 39, II I.

Soloway, H. B. (1974). Drug-induced bleeding. Amer. F. Clin. Path., 61, 622-626.

Thomas, D. P. (1978). Heparin in the prophylaxis and treatment of venous thromboembolism. Semin. in Hemat., 15, No. I, I-I7.

Todd, J. W., Frisbie, J. H., Rossier, A. B., AdAMs, D. F., Als, A. V., Armenia, R. J., SASSAHARA, A. A. \& Tow, D. E. (1976). Deep venous thrombosis in acute spinal cord injury: a comparison of I25 I fibrinogen leg scanning, impedance plethysmography and venography. Paraplegia, 14, 50-57.

Walsh, J. J. \& TRIBE, C. R. (I965). Phlebo-thrombosis and pulmonary embolism in paraplegia. Paraplegia, 3, 209-213.

Watson, H. (1968). Venous thrombosis and pulmonary embolism in spinal cord injury. Int. F. Paraplegia, 6, I13-I2I.

Watson, N. (I974). Anticoagulant therapy in the treatment of venous thrombosis and pulmonary embolism in acute spinal injury. Paraplegia, 12, 197-20I.

Wessler, S. (1974). Anticoagulant therapy. F. Amer. Med. Assn., 228, No. 6, 757-761.

Wessler, S. \& Gitel, S. (1976). Control of Heparin Therapy. Progress in Hemostasis and Thrombosis. Ed. by T. H. Spaet, Vol. III, p. 3 II .

WessleR, S. \& YIN, E. T. (I973). Theory and practice of minidose heparin in surgical patients. A status report. Circulation, 47, 67I-676. 